\title{
Argon Plasma Coagulation for the Treatment of Hemorrhagic Radiation Colitis
}

\author{
Mindy C.W. Lam Matthew Parliament \\ Clarence K.W. Wong
}

Cross Cancer Institute and Royal Alexandra Hospital, Division of Gastroenterology, Department of Medicine, University of Alberta, Edmonton, Alta., Canada

\section{Key Words}

Argon plasma coagulation · Radiation colitis $\cdot$ Rectal bleeding

\begin{abstract}
Radiation colitis is a common consequence of pelvic radiation. Its complications may include anemia due to chronic bleeding requiring transfusions. Many of these patients are managed with rectal medications which are often inadequate for control. Argon plasma coagulation (APC) has been well described for its efficacy in treating radiation proctitis. Here we present two cases in whom APC therapy was used to treat severe radiation colitis. We reviewed two cases originally seen at the regional cancer center (Cross Cancer Institute) in Edmonton, Alberta, Canada. Both patients received pelvic radiation for recurrent endometrial cancers and were referred for active bleeding secondary to radiation colitis that had required numerous transfusions. Radiation-induced telangiectasias were found from $10-50 \mathrm{~cm}$ in the sigmoid colon. Both patients had significant improvement of symptoms after one session of APC treatment set at 40-60 $\mathrm{W}$ and gas flow of $2.0 \mathrm{l} / \mathrm{min}$. There were no complications from the procedures. Neither patient required blood transfusions after the treatment with improvement in their hemoglobin levels and were doing well at 3-and 6-month follow-up. APC can be used effectively to provide immediate and sustained resolution of symptoms in patients with radiation colitis.
\end{abstract}

\section{Introduction}

Radiation colitis is a well-recognized complication of radiation therapy for pelvic malignancies, which include prostate, endometrial, cervical or bladder cancers. There are two forms of radiation colitis, acute and chronic. The acute form is usually self-limiting and lasts up to 3 months. The chronic or delayed form may present months 
or years after radiation exposure. Late complications of pelvic radiotherapy consists of bleeding, anemia, strictures, fistula or anorectal dysfunction, and have an incidence rate of $5-20 \%$ [1]. Radiation-induced mucosal damage results in epithelial changes such as fibrosis, microvascular alterations, thrombosis, telangiectasia and endothelial degeneration $[2,3]$. Patients often present with persistent rectal bleeding which may lead to iron deficiency anemia requiring blood transfusions. Additionally, reduced distensibility of the rectum due to fibrosis may result in tenesmus and in some cases rectal stricturing leading to difficulty in defecation $[1,4]$.

There have been numerous studies on the efficacy of argon plasma coagulation (APC) in the treatment of radiation proctitis. In contrast to conventional unipolar and bipolar electrocoagulation techniques, where adhesion of the probe to tissue and difficulty of assessing depth of thermal effect are major limitations, APC involves the delivery of unipolar diathermy current in a non-contact fashion, using the inert argon gas as the conducting medium [5]. In a study by Sebastian et al. [6], of 25 patients with persistent rectal bleeding and recurrent anemia, $81 \%$ achieved complete cessation of bleeding after a median of one treatment with APC; no complications resulted from the use of this modality. Other studies showed similar efficacies with potential complications such as rectal stricture [7] and recto-vaginal fistula [5]. There have also been case reports of methane gas fire and colonic explosion when using APC. However, complete bowel preparation and a full colonoscopy prior to APC treatment will drastically reduce this risk [8].

Although the evidence is strong for APC in the management of radiation proctitis, there are currently little data on the treatment of radiation colitis. Here we present two patients from the Cross Cancer Institute and Royal Alexandra Hospital in Edmonton, Alberta, in whom radiation colitis was successfully treated using APC.

\section{Case 1}

A 76-year-old female presented with an 8-month history of intermittent rectal bleeding. Her medical history included hypertension, previous cerebral vascular accident and an endometrial malignancy. She had a total abdominal hysterectomy, bilateral salpingo-oophorectomy, bilateral pelvic node sampling, omentectomy and staging laparotomy 3 years prior to referral. Pathology revealed grade 3 endometrial adenocarcinoma with heterogeneous serous papillary, undifferentiated and large cell neuroendocrine carcinoma elements. She completed a postoperative chemotherapy consisting of 4 cycles of intravenous carboplatin and etoposide at that time. Unfortunately, 1 year later she developed recurrent undifferentiated endometrial carcinoma in the vaginal mucosa in the suburethral position. She received a course of salvage radical radiotherapy and was treated with a combination of $15 \mathrm{MV}$ X-rays and $18 \mathrm{MeV}$ electrons with 4,500 cGy in 25 daily fractions to treat the perivaginal tissues, inguinal and pelvic lymph nodes. The residual perivaginal mass received a low dose rate interstitial brachytherapy boost of 2,535 cGy in $39 \mathrm{~h}$.

Grade 4 rectal bleeding began 10 months after completion of radiation therapy. She had received a total of 44 units of packed red blood cells over 8 months and her hemoglobin ranged from 51 to $118 \mathrm{~g} / \mathrm{l}$. Aside from colonoscopy by surgeons, she was not offered definitive therapies for her rectal bleeding.

A colonoscopy performed 14 months prior to referral with small routine biopsies revealed fibrosis of the lamina propria, consistent with chronic radiation damage. An incomplete colonoscopy performed 5 months prior to referral revealed inflammation and bleeding from the anal canal up to $35-40 \mathrm{~cm}$ proximally from the anal verge, consistent with radiation proctitis. After her referral to our 
clinic, a repeat colonoscopy revealed significant and diffuse sigmoiditis and proctitis up to $50 \mathrm{~cm}$ proximally from the anal verge ( $\underline{\text { fig. } 1}$ ).

The APC generator was set to a flow of $2 \mathrm{l} / \mathrm{min}$ with a power setting of $40 \mathrm{~W}$ for sigmoid colon applications and a power setting of $60 \mathrm{~W}$ for rectal therapy. Numerous punctate treatments which coagulated visible telangiectasias were performed. The patient had good hemostasis and tolerance for the procedure. Although she had experienced significant symptomatic improvement, rectal bleeding resumed 1 month post therapy, requiring 6 units of packed red blood cells transfusion over 2 months. A second procedure at 3 months revealed a significant reduction in the extent of colitis $(30 \mathrm{~cm})$ compared to the initial assessment. 40-50 applications of APC at $2 \mathrm{l} / \mathrm{min}$ and $60 \mathrm{~W}$ were performed with good hemostasis and tolerance by the patient (fig. 1). She did not require further blood transfusions for gastrointestinal bleeding after the second APC treatment. She had two subsequent sigmoidoscopies at 4 and 12 months after her last APC treatment which revealed excellent healing with no ulcers, strictures or fistulas (fig. 1).

\section{Case 2}

A 52-year-old female presented with a 3-month history of ongoing intermittent rectal bleeding and anemia requiring blood transfusion. She had a history of stage IIB, grade 3 adenosquamous endometrial carcinoma that was treated with total abdominal hysterectomy, bilateral salpingooophorectomy and pelvic node dissection 2.5 years before. Pathology at that time revealed direct tumor extension to the endocervix with myometrial invasion to within $1 \mathrm{~mm}$ of the serosa and multifocal lymphovascular space invasion. She underwent adjuvant postoperative external beam radiotherapy, consisting of $15 \mathrm{MV}$ X-rays with a 4-field beam arrangement treating the pelvic lymph nodes, parametria and vaginal vault at a dose of 4,500 cGy in 25 daily fractions over 5.5 weeks. Additionally, she received a high dose rate brachytherapy boost by a $3.5 \mathrm{~cm}$ diameter cylindrical vaginal applicator delivering a dose of 1,800 cGy in 3 daily fractions over 3 days.

Unfortunately, a $4.4 \times 3.6 \mathrm{~cm}$ recurrent periurethral and perivaginal mass with pathology consistent with recurrence of grade 3 adenosquamous carcinoma of the endometrium was found 11 months later. This led to a salvage course of external beam radiotherapy consisting of $15 \mathrm{MV}$ $\mathrm{X}$-rays using a 3D conformal 4-field technique at a dose of 4,500 cGy in 25 daily fractions and low dose interstitial radiotherapy boost of 2,353 cGy in $47 \mathrm{~h}$. The brachytherapy session was terminated prematurely due to an acute episode of dyspnea, fever and hypoxemia that was thought to result from a combination of atelectasis, narcotic-induced hypoventilation and possible urinary tract infection. In order to adequately treat her recurrence, a small portion of the rectal mucosa received an estimated cumulative dose of $>10,000$ cGy.

Grade 4 rectal bleeding began 10 months after her last radiation therapy and her hemoglobin remained around 75-85 g/l despite 7 units of packed red blood cells transfusion over 3 months. She had not received definitive therapy for her rectal bleeding prior to presentation. Other significant medical history includes diabetes and coronary artery disease with a previous myocardial infarct event.

We proceeded with endoscopic investigations. Esophagogastroduodenoscopy to the third portion of the duodenum was unremarkable. Colonoscopy revealed diffuse areas of telangiectasia consistent with severe radiation proctitis and sigmoiditis $15 \mathrm{~cm}$ proximal to the rectosigmoid junction.

The APC generator gas flow was set to $2 \mathrm{l} / \mathrm{min}$ with a power of $60 \mathrm{~W}$ and $30-40$ applications were applied with good hemostasis and tolerance by the patient. After one APC treatment, her hemoglobin improved and remained stable at $90 \mathrm{~g} / \mathrm{l}$. At 3-month follow-up, she had significant reduction in telangiectasias; however, due to the extent of the lesions, further APC at $60 \mathrm{~W}$ was applied. At 10 months, she had return of occasional bleeding per rectum and slight decrease in her hemoglobin, and a third colonoscopy with APC was performed. There was approximately $8 \mathrm{~cm}$ of mild colitis with a $2.5 \mathrm{~cm}$ ulcer that was $8 \mathrm{~cm}$ proximal to the anal verge. APC set to $2 \mathrm{l} / \mathrm{min}$ and $60 \mathrm{~W}$ was applied to 20 different areas with good hemostasis and tolerance by the patient. She received one unit of packed red blood cells 1 month after her third and last APC session. She did not require further blood transfusion for gastrointestinal bleeding and her hemoglobin was stable at $109 \mathrm{~g} / \mathrm{l} 3$ years post 
therapy. She developed rectovaginal fistula secondary to radiation therapy 3.5 years after her last APC treatment.

\section{Discussion}

Radiation-induced enteropathy is a very common and disabling complication of pelvic radiotherapy in up to $10 \%$ of cases [9]. It significantly decreases the quality of life of patients by interfering with the physical, psychological and social aspects of their lives [10]. Medical complications resulting from anemia, stricturing, ulceration and fistulization can also occur.

There are different medical therapies for radiation enteropathy, including steroids, antibiotics, antioxidants, sulfasalazine, short-chain fatty acids, sucralfate enemas and formalin instillation [9, 11-17]. Denton et al. [18] summarized the evidence behind each therapy. Although many single-center case series show evidence to support each of these medical interventions, endoscopic therapy allows for successful and immediate management of bleeding from radiation colitis. Other endoscopic therapies are being explored, such as mucosal focal radiofrequency ablation [19]. Surgical management is reserved for cases of failed conservative treatments and is often associated with high morbidity and mortality $[9,20,21]$.

Despite the widely accepted use of APC in radiation proctitis [22-26], there are few reports or studies on the use of APC in radiation colitis. In this report, we present two very successful cases in whom APC was used to manage radiation-induced colitis. Both patients presented with chronic rectal bleeding and chronic anemia requiring multiple blood transfusions 10 months post radiation therapy. After treatment with APC, bleeding decreased significantly and, more important, transfusions were no longer required. The extent of colitis and symptoms experienced by the patients drastically improved after treatment. The outcomes of APC treatments in these two cases have been assessed up to 3.5 years post therapy for both patients, and neither required further blood transfusions for gastrointestinal bleeding.

It is also interesting to note that in case 1 , brachytherapy was placed into the anterior perivaginal tissues. With the insertion of a vaginal spacer physically displacing the posterior vaginal wall during treatment, the cumulative rectal dose would have been significantly less compared to case 2 . Therefore, case 1 may have an intrinsic or a genetic predisposition to late radiation injury.

It is important to recognize that radiation colitis is common among patients with pelvic radiation, and our current management of many of these patients using conventional medical therapy is not adequate in achieving proper control of patients' hemodynamics and their symptoms. The successful outcome of APC in the management of radiation colitis in our experience warrants the use of APC in similar cases. An assessment and comparison of this modality to other currently available treatments in larger-scale studies are needed. It is also important to compare the quality of life of patients between the different therapies in order to assess the effect of these treatments on their livelihood. Our experience suggests that APC should be considered as first-line therapy when treating radiation colitis. 

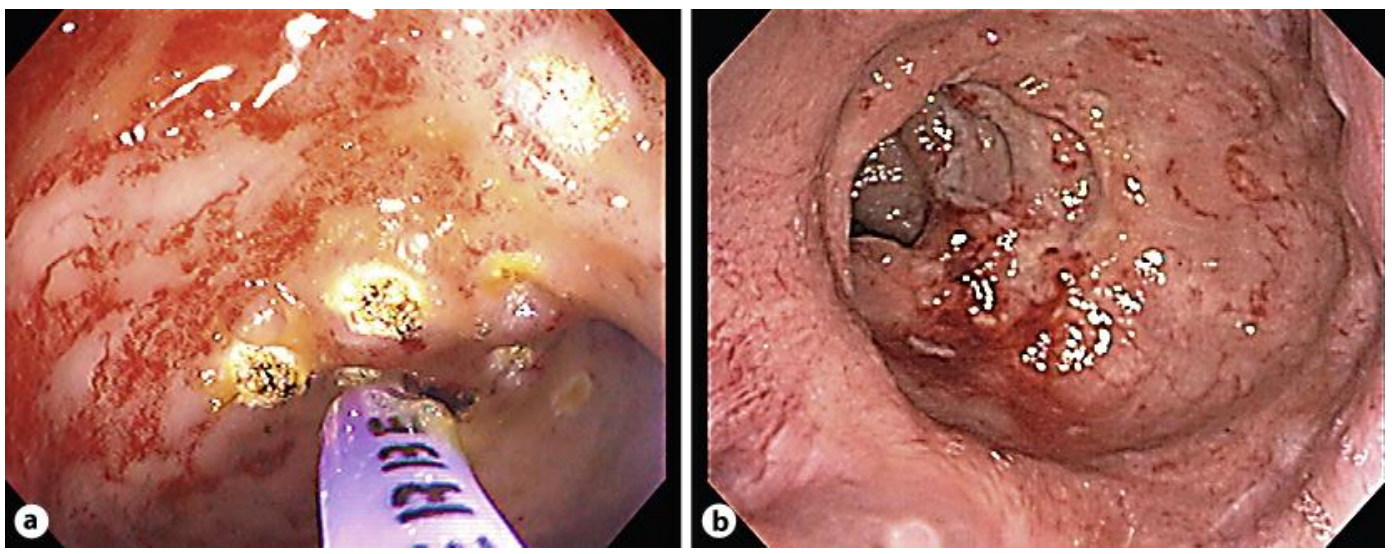

Fig. 1. a Initial colonoscopy. Sigmoid colon with areas of scaring from APC treatment, the APC probe can be seen. b Follow-up colonoscopy 13 months post initial APC treatment. Sigmoid colon.

\section{References}

1 Leiper K, Morris AI: Treatment of radiation proctitis. Clin Oncol (R Coll Radiol) 2007;19:724-729.

$\checkmark 2$ Haboubi NY, Schofield PF, Rowland PL: The light and electron microscopic features of early and late phase radiation-induced proctitis. Am J Gastroenterol 1988;83:1140-1144.

3 MacNaughton WK: Review article: New insights into the pathogenesis of radiation-induced intestinal dysfunction. Aliment Pharmacol Ther 2000;14:523-528.

-4 Gilinsky NH, Burns DG, Barbezat GO, Levin W, Myers HS, Marks IN: The natural history of radiationinduced proctosigmoiditis: an analysis of 88 patients. Q J Med 1983;52:40-53.

5 Rotondano G, Bianco MA, Marmo R, Piscopo R, Cipolletta L: Long-term outcome of argon plasma coagulation therapy for bleeding caused by chronic radiation proctopathy. Dig Liver Dis 2003;35: 806-810.

6 Sebastian S, O'Connor H, O’Morain C, Buckley M: Argon plasma coagulation as first-line treatment for chronic radiation proctopathy. J Gastroenterol Hepatol 2004;19:1169-1173.

7 Kaassis M, Oberti E, Burtin P, Boyer J: Argon plasma coagulation for the treatment of hemorrhagic radiation proctitis. Endoscopy 2000;32:673-676.

8 Ben-Soussan E, Antonietti M, Savoye G, Herve S, Ducrotte P, Lerebours E: Argon plasma coagulation in the treatment of hemorrhagic radiation proctitis is efficient but requires a perfect colonic cleansing to be safe. Eur J Gastroenterol Hepatol 2004;16:1315-1318.

9 Babb RR: Radiation proctitis: a review. Am J Gastroenterol 1996;91:1309-1311.

10 Abayomi J, Kirwan J, Hackett A, Bagnall G: A study to investigate women's experiences of radiation enteritis following radiotherapy for cervical cancer. J Hum Nutr Diet 2005;18:353-363.

11 Kochhar R, Patel F, Dhar A, Sharma SC, Ayyagari S, Aggarwal R, Goenka MK, Gupta BD, Mehta SK: Radiation-induced proctosigmoiditis. Prospective, randomized, double-blind controlled trial of oral sulfasalazine plus rectal steroids versus rectal sucralfate. Dig Dis Sci 1991;36:103-107.

12 Talley NA, Chen F, King D, Jones M, Talley NJ: Short-chain fatty acids in the treatment of radiation proctitis: a randomized, double-blind, placebo-controlled, cross-over pilot trial. Dis Colon Rectum 1997;40:1046-1050.

13 Kochhar R, Sriram PV, Sharma SC, Goel RC, Patel F: Natural history of late radiation proctosigmoiditis treated with topical sucralfate suspension. Dig Dis Sci 1999;44:973-978.

14 Kochhar R, Sharma SC, Gupta BB, Mehta SK: Rectal sucralfate in radiation proctitis. Lancet 1988;2:400.

15 Saclarides TJ, King DG, Franklin JL, Doolas A: Formalin instillation for refractory radiation-induced hemorrhagic proctitis. Report of 16 patients. Dis Colon Rectum 1996;39:196-199. 
16 Tsujinaka S, Baig MK, Gornev R, de la Garza C, Hwang JK, Sands D, Weiss EG, Nogueras JJ, Efron J, Vernava AM 3rd, Wexner SD: Formalin instillation for hemorrhagic radiation proctitis. Surg Innov 2005;12:123-128.

17 Kennedy M, Bruninga K, Mutlu EA, Losurdo J, Choudhary S, Keshavarzian A: Successful and sus tained treatment of chronic radiation proctitis with antioxidant vitamins E and C. Am J Gastroenterol 2001;96: 1080-1084.

-18 Denton AS, Andreyev HJ, Forbes A, Maher EJ: Systematic review for non-surgical interventions for the management of late radiation proctitis. Br J Cancer 2002;87:134-143.

19 Zhou C, Adler DC, Becker L, Chen Y, Tsai TH, Figueiredo M, Schmitt JM, Fujimoto JG, Mashimo H: Effective treatment of chronic radiation proctitis using radiofrequency ablation. Therap Adv Gastroenterol 2009;2:149-156.

20 Browning GG, Varma JS, Smith AN, Small WP, Duncan W: Late results of mucosal proctectomy and colo-anal sleeve anastomosis for chronic irradiation rectal injury. Br J Surg 1987;74:31-34.

-21 Tagkalidis PP, Tjandra JJ: Chronic radiation proctitis. ANZ J Surg 2001;71:230-237.

-22 Kwon RS, Carr-Locke DL: Are we making progress with argon plasma coagulation in chronic radiation proctopathy? J Gastroenterol Hepatol 2005;20:171-172.

-23 Tam W, Moore J, Schoeman M: Treatment of radiation proctitis with argon plasma coagulation. Endoscopy 2000;32:667-672.

24 Taieb S, Rolachon A, Cenni JC, Nancey S, Bonvoisin S, Descos L, Fournet J, Gerard JP, Flourie B: Effective use of argon plasma coagulation in the treatment of severe radiation proctitis. Dis Colon Rectum 2001;44:1766-1771.

-25 Karamanolis G, Triantafyllou K, Tsiamoulos Z, Polymeros D, Kalli T, Misailidis N, Ladas SD: Argon plasma coagulation has a long-lasting therapeutic effect in patients with chronic radiation proctitis. Endoscopy 2009;41:529-531.

-26 Swan MP, Moore GT, Sievert W, Devonshire DA: Efficacy and safety of single-session argon plasma coagulation in the management of chronic radiation proctitis. Gastrointest Endosc 2010;72:150-154. 